PSICOLOGÍA

IBEROAMERICANA
Psicología Iberoamericana ISSN: 1405-0943

revista.psicologia@ibero.mx

Universidad Iberoamericana, Ciudad de México México

\title{
Psicología basada en la evidencia en tiempos del covid en México
}

\section{Camacho Gutiérrez, Everardo}

Psicología basada en la evidencia en tiempos del covid en México

Psicología Iberoamericana, vol. 29, núm. Esp.3, e293414, 2021

Universidad Iberoamericana, Ciudad de México, México

Disponible en: https://www.redalyc.org/articulo.oa? $\mathrm{id}=133968747003$

DOI: https://doi.org/10.48102/pi.v29i3.414

\section{(c) (1)}

Esta obra está bajo una Licencia Creative Commons Atribución 4.0 Internacional. 


\title{
Editorial
}

\section{Psicología basada en la evidencia en tiempos del covid en México}

\author{
Evidence-based psychology in times of COVID in Mexico \\ Everardo Camacho Gutiérrez ecamacho@iteso.mx \\ Instituto Tecnológico y de Estudios Superiores de Occidente (ITESO), \\ México \\ https://orcid.org/0000-0002-8592-7897
}

Psicología Iberoamericana, vol. 29, núm. Esp.3, e293414, 2021

Universidad Iberoamericana, Ciudad de México, México

DOI: https://doi.org/10.48102/ pi.v29i3.414

Redalyc: https://www.redalyc.org/ articulo.oa?id=133968747003
La producción de conocimiento en países latinoamericanos es muy inferior en relación a los países anglosajones y de primer mundo (VeraVillarroel et al., 2011). En parte, esta diferencia se explica en función del apoyo económico que los gobiernos de los países destinan a la promoción de la investigación. En este contexto, México no ha podido tener destinado aún el $1 \%$ del PIB para el desarrollo de la ciencia y la tecnología (Torres-Samuel et al., 2020). Ante estas condiciones, los científicos mexicanos hacen lo que se puede, en el entendido de que muchos de los fenómenos que se pudieran estudiar, carecen de conocimiento local suficiente. Las consecuencias son que el conocimiento que tenemos de muchos fenómenos proviene del extranjero, así como también la tecnología que dicho conocimiento deriva. Somos grandes consumidores de dicho conocimiento que tiene para nosotros un costo alto y que además no está adaptado a nuestras condiciones culturales, por más que se busque estandarizar las condiciones socioculturales tan variadas de nuestro país a una condición sociocultural occidental "estándar".

Otra consecuencia vinculada a esta escasez de producción, es que las autoridades responsables de políticas públicas, no tienen una cultura instalada de toma de decisiones basada en el conocimiento científico que se genera sobre los fenómenos que deciden.

Por otra parte, el fenómeno de la epidemia del Covid-19 llegó al mundo hace 18 meses para trastocar la vida cotidiana de millones de personas, y una de las pocas certezas que tenemos al respecto, es que las condiciones de restricción generadas por la pandemia y la amenaza potencial del virus, seguirán durante todavía un período largo de tiempo, para que se resuelva y termine, lo cual no es una tarea evidentemente fácil (OPS, 2020).

En muchos países, inmediatamente se han generado múltiples proyectos de investigación que generen un conocimiento que facilite y promueva la comprensión múltiple del fenómeno de la pandemia y sus múltiples efectos, con la intención de orientar las políticas públicas en torno a este problema de salud y que sea eficaz y eficiente. 
Es evidente entonces que una de las consecuencias importantes del cambio de hábitos de vida generados por la pandemia ha afectado directamente la salud mental de grandes sectores de la población y ha tenido consecuencias en sus patrones de relación con otros, en el ámbito laboral, en su estado de salud biológica, así como en su capacidad de adaptación a condiciones de amenaza real y también en su estado de ánimo, sus emociones y su calidad de vida en general (Larios-Navarro et al., 2020; Ribot Reyes et al., 2020).

En condiciones normales, la salud mental no había ocupado la preponderancia y relevancia que ha adquirido bajo las condiciones de pandemia en donde se ha hecho evidente, su importancia crucial, así como la vulnerabilidad de grandes sectores de la población si no se desarrollan estrategias preventivas y de intervención adecuadas (Mariscal, 2020). La OMS considera que la afectación psicosocial producida por la pandemia del Covid, tendrá efectos cuando menos durante los tres años subsiguientes al término de la pandemia (González García \& Ramírez Nardiz, 2020).

Bajo estas condiciones diferentes, el movimiento de psicología basado en la evidencia (Mustaca, 2011) destaca como una perspectiva importante y relevante que orienta al desarrollo de investigación aplicada que permita el desarrollo de estrategias tanto de diagnóstico como de intervención que procuren ser eficaces y eficientes y que puedan ser aplicados a amplios grupos de la población de forma probada y generalizada.

Actualmente, se conoce poco sobre el impacto directo e indirecto en la población por la pandemia COVID-19. Sabemos que el impacto psicosocial en la población ha afectado diversas áreas. Por ello, es muy relevante generar conocimiento en nuestro país sobre el fenómeno y cómo impacta la Salud Mental, el bienestar y la calidad de vida de la población.

Desde la mirada profesional, orientada a analizar la dimensión psicosocial, se requiere el aporte, la reflexión, la investigación y los datos que conlleva, el análisis, de múltiples personas orientadas a generar conocimiento de nuestro contexto, que permita, desde una reducida y acotada comprensión, la posibilidad de desarrollar diagnósticos claros, e intervenciones tanto remediales como preventivas innovadoras y creativas como por ejemplo el uso de tecnología computarizada para intervenir a distancia, para mejorar la calidad de vida de muchas personas bajo las condiciones extraordinarias que compartimos en estos momentos.

Esto ha posibilitado que colegas de todo el país, y otros desde el extranjero, colaboren desde su propia perspectiva y desde su propio trabajo de síntesis, para que con generosidad se pueda producir un crisol de confluencias, que en la sinergia, nos permita tener una percepción integrada, a partir del ensamblaje de las múltiples piezas que conforman parte de este rompecabezas. Percibir lo que no es aparente, valorar la imagen que emerge en el revelado de una fotografía y describir el movimiento dinámico de un fenómeno que no se detiene y es diferente de un momento a otro, son retos que, en este trabajo, se han asumido colectivamente entre todos los colaboradores. 
Es así, como se ha armado este número especial de la Revista de Psicología Iberoamericana que permite tener información fresca y objetiva en torno a diferentes microcosmos, con poblaciones diversas, desde estudiantes universitarios, de secundaria y de preescolar de distintos contextos, de trabajadores universitarios a familiares de personas enfermas por Covid, que viven la preocupación del proceso o enfrentan el duelo, de comunidades solidarias de bajos recursos a colonias de niveles socioeconómicos altos. Grupos familiares completos, en servicios telefónicos de acompañamiento y grupos más grandes como comunidades y barrios. En el análisis del impacto de la información en los medios masivos de comunicación y las redes, en los rumores y el proceso de desinformación.

Esta información es potencialmente transformadora en la medida en que es conocimiento generado en el contexto de nuestro propio país, desde nuestras propias condiciones tanto físicas, espaciales y culturales, así como para las personas que toman decisiones en el nivel de la Salud Pública y los propios potenciales beneficiarios directos de este conocimiento.

Vaya pues como un aporte de conocimiento sistematizado y objetivo, que potencialmente pueda ser útil para transformar la realidad de otros connacionales, en la dirección de mejoría bajo estas condiciones que nos ha tocado vivir.

\section{Referencias}

González García, A., \& Ramírez Nárdiz, A. (2020). Análisis y reflexiones sobre el COVID-19: pandemia y postpandemia. J.M. Bosch editor.

Larios-Navarro, A., Bohórquez-Rivero, J., Naranjo-Bohórquez, J., \& SáenzLópez, J. (2020). Impacto psicológico del aislamiento social en el paciente comórbido: a propósito de la pandemia COVID-19. Revista Colombiana de Psiquiatria, 49(4), 227-228. https://doi.org/10.1016/j.rcp.2020.07.0 02

Mariscal, S. M. A. C. (2020). La salud mental ante la pandemia de la covid-19. Pluralidady Consenso, 10(44), 128-135.

Mustaca, A. E. (2011). Evaluación objetiva de los tratamientos psicológicos: modelos basados en la ciencia. Revista Colombiana de Psicología, 20(1), 99-106.

Organización Panamericana de la Salud [OPS]. (2020). La OMS caracteriza al COVID-19 como una epidemia. https://www.paho.org/hq/index.php?op tion $=$ com_content\&view=article\&id=15756:who-characterizes-covid19-as-a-pandemic\&Itemid $=1926 \&$ lang $=$ es

Ribot Reyes, V. D. L. C., Chang Paredes, N., \& González Castillo, A. L. (2020). Efectos de la COVID-19 en la salud mental de la población. Revista Habanera de Ciencias Médicas, 19(1).

Torres-Samuel, M., Vásquez Stanescu, C. L., \& Crissien Borrero, T. J. (2020). Eficiencia técnica de la investigación y desarrollo, ciencia y tecnología, educación e innovación en países Latinoamericanos. RISTI-Revista Iberica de Sistemas e Tecnologias de Informacao, E29(5), 582-594. 
Vera-Villarroel, P., López-López, W., Lillo, S., \& Silva, L. M. (2011). La producción científica en psicología latinoamericana: un análisis de la investigación por países. Revista Latinoamericana de Psicología, 43(1), 95-104. http://dx.doi.org/10.14349/rlp.v43i1.613 